AperTO - Archivio Istituzionale Open Access dell'Università di Torino

\title{
Reperfusion damage to the bile canaliculi in transplanted human liver.
}

\section{This is the author's manuscript}

Original Citation:

\section{Availability:}

This version is available http://hdl.handle.net/2318/29962

since

Terms of use:

Open Access

Anyone can freely access the full text of works made available as "Open Access". Works made available under a Creative Commons license can be used according to the terms and conditions of said license. Use of all other works requires consent of the right holder (author or publisher) if not exempted from copyright protection by the applicable law. 


\title{
In Situ Determination by Surface Chemiluminescence of Temporal Relationships Between Evolving Warm Ischemia-Reperfusion Injury in Rat Liver and Phagocyte Activation and Recruitment
}

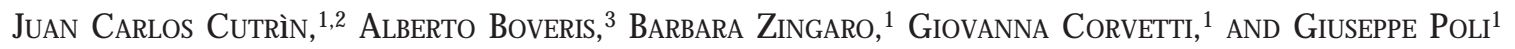

\begin{abstract}
Liver ischemia-reperfusion is characterized by an increased oxygen-dependent free radical chain-reaction rate and an increased steady-state concentration of reactive oxygen species. The aim of this study was to evaluate the in situ generation of reactive oxygen species and its relationship with phagocyte activation and recruitment in reperfused rat liver. Rat livers were subjected to 2 hours of selective lobular ischemia and reperfusion for up to 12 hours. The following parameters were determined: in situ liver chemiluminescence, understood to reflect the tissue steady-state concentration of singlet oxygen $\left({ }^{1} \mathrm{O}_{2}\right)$; myel operoxidase tissue activity; the number of neutrophils; and the degree of necrosis. An early chemiluminescence burst was measured after $\mathbf{3 0}$ minutes of blood reflow (early phase of oxidative stress), followed by a relapse and a further increase after 4 to 12 hours of reperfusion (late phase of oxidative stress). Both early and late phases were modified by pretreatment with gadolinium chloride $\left(\mathrm{G} \mathrm{dCl}_{3}\right)$, pointing to a key role of the Kupffer cells. Neutrophils infiltrated into the liver, myeloperoxidase activity, in situ chemiluminescence, and necrosis were found to be strongly correlated over the 4- to 12-hour reperfusion period ( $r=.960$; average of the 4 correlation coefficients). Together with resident phagocytes, neutrophil recruitment and activation appear to provide a major contribution to the increase of oxygendependent free-radical reactions and amplification of liver reperfusion damage. Surface chemiluminescence appears to properly describe the in situ and in vivo progressive organization of the acute inflammatory response with phagocytemediated liver injury. (Hepatology 2000;31:622-632.)
\end{abstract}

Abbreviations: ${ }^{1} \mathrm{O}_{2}$, singlet oxygen; $\mathrm{GdCl}_{3}$, gadolinium chloride; $\mathrm{PMA}$, phorbol 12-myristate 13 -acetate; $\mathrm{O}_{2}^{-}$, superoxide anion; $\mathrm{ONOO}^{-}$, peroxynitrite; $\mathrm{HO}$, hydroxyl radical

From the ${ }^{1}$ Department of Clinical and Biological Sciences, University of Turin, ASL San Luigi Gonzaga, Orbassano, Turin, Italy; ${ }^{2}$ A.Fa.R.-Fatebenefratelli Hospital, S. Maurizio Canavese, Turin, Italy; and 'Laboratory of Free Radical Biology, School of Pharmacy and Biochemistry, University of Buenos Aires, Argentina.

Received February 22, 1999; accepted December 2, 1999.

Supported by grants from the Universities of Buenos Aires and Turin; the Argentine National Research Council and the Italian Ministry for the University, National Projects 1998 and 1999; and the Italian National Research Centre "Progetto Finalizzato Biotecnologie."

Address reprint requests to: Juan C. Cutrìn, M.D., Ph.D., Dipartimento di Scienze Cliniche e Biologiche,Università di Torino, ASL San Luigi Gonzaga,Regione Gonzole 10,10043 Orbassano, Torino, I talia. E-mail: juan.cutrin@unito.it; fax: 39-011-670-8124.

Copyright (c) 2000 by the American Association for the Study of Liver Diseases.

0270-9139/00/3103-0012\$3.00/0
Oxygen free radicals have long been indicated as being responsible for ischemia-reperfusion-induced liver damage. 1-3 $^{-3}$ The increased production of oxygen radicals and the postischemic injury of the liver were subsequently recognized to have a 2-phase time course: an early phase, from reflow up to about 30 to 60 minutes of reperfusion, and a late phase, from approximately 3 to 24 hours of blood reflow. ${ }^{4-8}$ The first phase is understood as an overproduction of oxygen radicals in activated Kupffer cells $s^{4,7}$ and in the mitochondria of hepatocytes and of endothelial cells, where oxygen reflow encounters highly reduced respiratory chains. ${ }^{6-8}$ The second phase appears to follow the infiltration and activation of neutrophils in the liver parenchyma. ${ }^{4,5,9-16}$ The first phase, which includes increased nitric oxide (NO) production by liver mitochondria ${ }^{17}$ and Kupffer cells, ${ }^{18,19}$ initiates the signal transduction processes that promote neutrophil accumulation in the liver. $9,10,20$

Although many studies have reported neutrophil infiltration causing liver injury after ischemia-reperfusion, the contribution of activated neutrophils together with residential phagocytes to the in situ generation of oxygen free radicals has not yet been clarified in the reperfused liver. In this study, the level s of singlet oxygen $\left({ }^{1} \mathrm{O}_{2}\right)$ in the tissue were monitored by chemiluminescence in the in situ-reperfused liver as a marker of oxidative stress, and myeloperoxidase activity was taken as a marker of neutrophil activation. Surface organ chemiluminescence, by measuring the photons emitted by the tissue, determines: 1) directly, the steady-state concentration of ${ }^{1} \mathrm{O}_{2}$ and the electronically excited state of molecular oxygen; and 2) indirectly, the rate of free radical chain reactions occurring in the tissue.21-23 Liver surface chemiluminescence has been used to assess the increased steady-state concentration of ${ }^{1} \mathrm{O}_{2}$, after rat liver ischemiareperfusion, ${ }^{6-8}$ and mouse liver necrosis after acetaminophen ${ }^{24}$ and fenofibrate ${ }^{25}$ administration.

\section{MATERIALS AND METHODS}

Animals. Male Wistar rats weighing 180 to $220 \mathrm{~g}$ were used. Animals were fed a chow diet devoid of vitamins A, C, and other antioxidants, with the exception of vitamin E ( $50 \mathrm{mg} / \mathrm{kg})$ (Cargill, Buenos Aires, Argentina), and with water ad libitum, and maintained under 12-hour light/dark cycles. To block Kupffer cell activity, one group of rats was pretreated with gadolinium chloride $\left(\mathrm{GdCl}_{3}\right)$ at 10 $\mathrm{mg} / \mathrm{kg}$ body weight diluted in sterile $0.9 \% \mathrm{NaCl}$ solution and administered through the tail vein 24 hours before ischemiareperfusion. Another group of rats (controls) received an equal 
volume of saline solution. Animals received humane care in compliance with institutional guidelines.

Experimental Model. A model of lobar hepatic ischemia-reperfusion was used. The rats were injected with heparin $(400 \mathrm{IU} / \mathrm{kg}$ body weight, intraperitoneally) and then anesthetized with sodium pentobarbital ( $50 \mathrm{mg} / \mathrm{kg}$ body weight, intraperitoneally) diluted in sterile $0.9 \% \mathrm{NaCl}$ solution. The liver was exposed by a midline laparotomy and the liver lobes moved gently to expose the hilum. Atraumatic Glober bulldog clamps (Roboz Surgical Instrument Co., Washington, DC) were used to interrupt the portal venous and the hepatic arterial blood supply to the right lobes, thus rendering ischemia about one third of the total hepatic mass. The medial, left lateral, and caudate lobes (nonischemic lobes), retaining an intact portal and arterial inflow and venous outflow, were used as control tissue. Hepatic ischemia was maintained for 2 hours with the abdominal cavity gently closed and the animals placed under warming lamps to keep body temperature constant. After declamping, the abdomen was closed with 3-0 silk, and the animals were housed and provided with food and water ad libitum until a second laparotomy was performed 4, 8, or 12 hours after reperfusion.

Spontaneous Liver Surface Chemiluminescence. The spontaneous surface chemiluminescence of the right lateral (ischemic) and of the nonischemic lobes of the in situ liver was monitored using a photon counter (J ohnson Research Foundation, University of Pennsylvania, Philadelphia, PA) (Fig. 1), with a model 9658 photomultiplier responsive over the range of 350 to $850 \mathrm{~nm}$ (Thorn EMI, Middlesex, England) as described elsewhere. ${ }^{21-23}$ Chemiluminescence in the intact organ is the result of different photoemissive reactions: 1) ${ }^{1} \mathrm{O}_{2}$

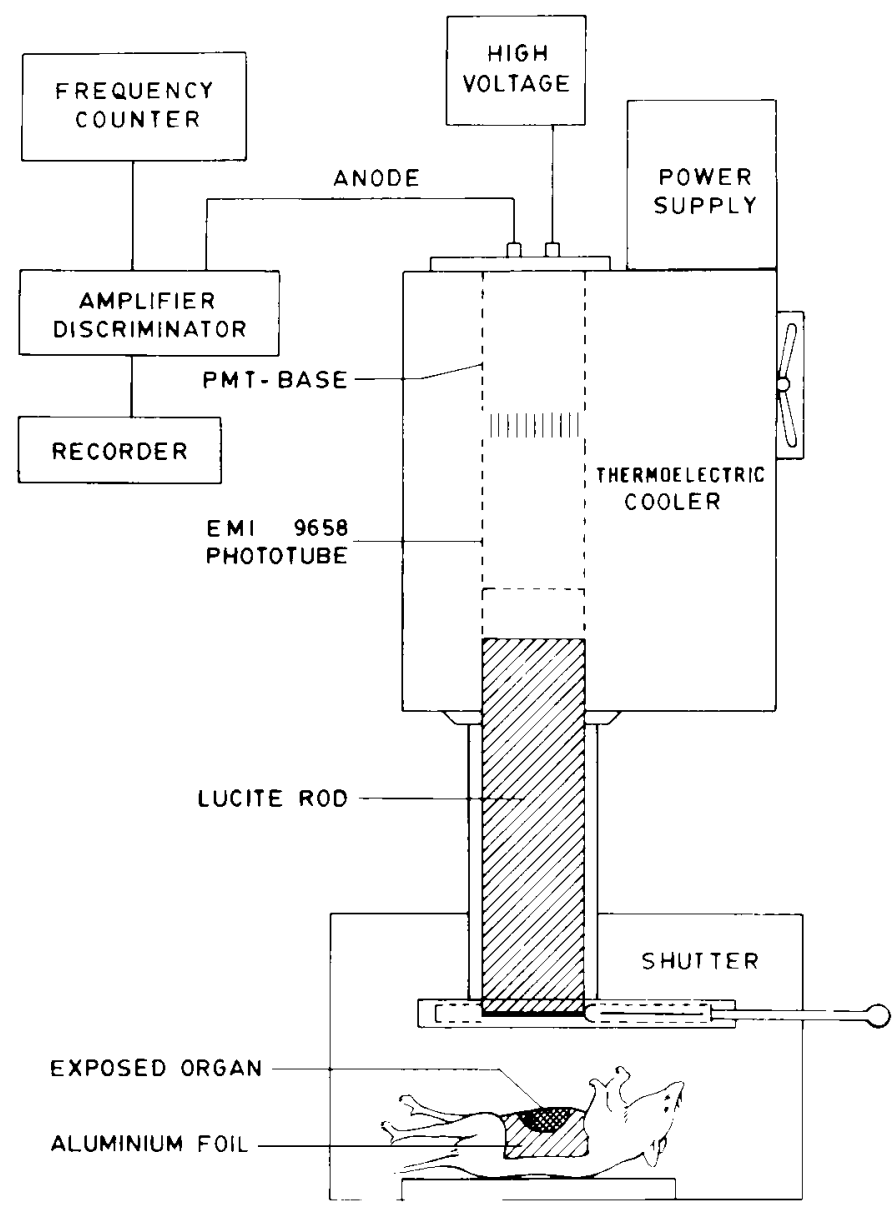

FIG. 1. Diagram of the photon-counting apparatus adapted for measuring in situ organ chemiluminescence. The lucite rod used as an optical coupler is placed in front of the liver exposed in situ. PMT, photomultiplier tube.

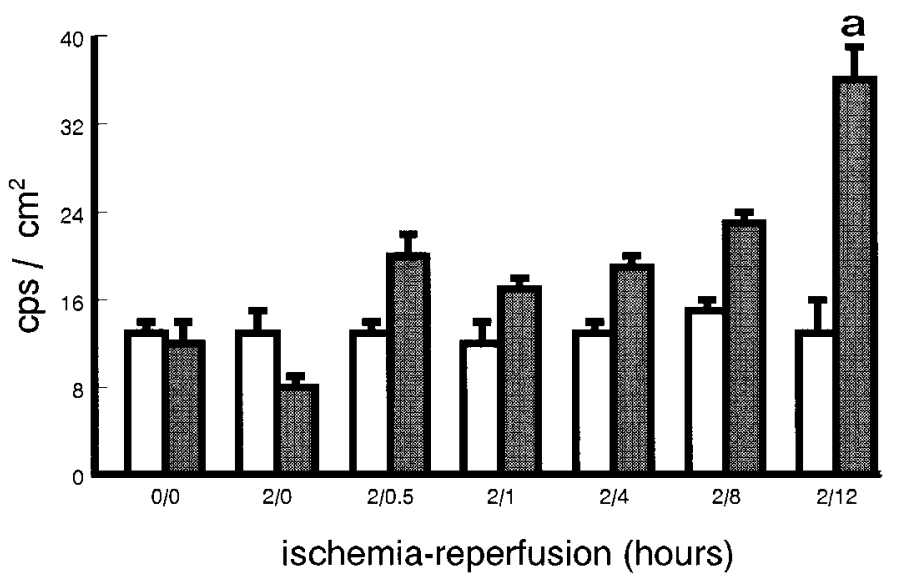

FIG. 2. Rat liver chemiluminescence after ischemia-reperfusion. Experimental details are given in Materials and Methods. Spontaneous chemiluminescence before the cycle of ischemia-reperfusion (0/0); after 2 hours of ischemia (2/0); after 2 hours of ischemia and 0.5 hours of reperfusion (2/0.5); after 2 hours of ischemia and 1 hour of reperfusion ( $2 / 1$; after 2 hours of ischemia and 4 hours of reperfusion (2/4); after 2 hours of ischemia and 8 hours of reperfusion (2/8); and after 2 hours of ischemia and 12 hours of reperfusion (2/12). a, significantly different from $0 / 0,2 / 0,2 / 1$ ischemic lobes $(P<.05)$. ( $\square)$, Nonischemic lobes; $(\square)$, ischemic lobe.

dimol emission; and 2) formation of 1,2-dioxetane derivatives, either from the lipid peroxidation free radical process or from the reaction of ${ }^{1} \mathrm{O}_{2}$ with double bonds, facilitating the generation of excited carbonyl groups after rupture of the carbon-carbon and oxygen-oxygen bonds. ${ }^{21-23}$ Emission was expressed in counts per second per square centimeter of liver surface $\left(\mathrm{cps} / \mathrm{cm}^{2}\right)$. Spectral analysis of liver chemiluminescence was performed with cut-off Kodak Wratten filters (Eastman Kodak, Rochester, NY) as described elsewhere. ${ }^{26}$

Sample Handling. At the end of each experimental period, the animals were killed by exsanguination under pentobarbital anesthesia. Samples from the ischemic right lateral lobes and the nonischemic lobes (controls) were taken in terminal procedures and bisected for biochemical and morphological assays.

Myeloperoxidase Activity. Myeloperoxidase activity was measured by a modification of the technique described by Krawisz et al. ${ }^{27}$ Briefly, liver samples (0.5-1.0 g wet weight) were freeze-thawed and homogenized $(1: 9, \mathrm{wt} / \mathrm{vol})$ in $50 \mathrm{mmol} / \mathrm{L}$ potassium phosphate buffer $(\mathrm{pH} 6.0)$, containing $0.5 \%$ hexadecyltrimethyl-ammonium bromide. The homogenates were sonicated during 90 seconds, centrifuged $\left(6,000 \mathrm{rpm} / 30 \mathrm{~min}\right.$ at $\left.4^{\circ} \mathrm{C}\right)$ and the supernatant assayed for myeloperoxidase activity. An aliquot $(0.25-0.75 \mathrm{~mL})$ was added to $2.9 \mathrm{~mL}$ of $50 \mathrm{mmol} / \mathrm{L}$ potassium phosphate buffer $(\mathrm{pH} 6.0)$, containing $40 \mathrm{mmol} / \mathrm{L}$ of 0 -dianisidine-dihydrochloride and 40 $\mathrm{mmol} / \mathrm{L} \mathrm{H}_{2} \mathrm{O}_{2}$. The changes in absorbance at $460 \mathrm{~nm}$ were spectrophotometrically measured at room temperature. One unit of myeloperoxidase activity was defined as the amount of enzyme that degrades $1 \mu \mathrm{mol}$ peroxide per minute at $25^{\circ} \mathrm{C}$. The results were expressed as units per gram of wet tissue. Liver tissue contains substantial amounts of glutathione peroxidase, catalase, as well as hemoglobin, which compete with myeloperoxidase for $\mathrm{H}_{2} \mathrm{O}_{2}$. The use of hexadecyltrimethyl-ammonium bromide in the homogenization buffer allows for the solubilization of the myeloperoxidase bound to the granular membranes, and at the same time for the inhibition of the pseudoperoxidase activity of the above proteins by destroying their heme nucleus. ${ }^{28}$

Morphological Determinations. Fragments of liver $(1.0 \times 0.5 \times 0.3$ $\mathrm{cm}$ ) were fixed overnight in $4 \%$ formaldehyde in $50 \mathrm{mmol} / \mathrm{L}$ potassium phosphate buffer $(\mathrm{pH} \mathrm{7.4)}$ at room temperature, dehydrated in graded alcohol solutions, and embedded in paraffin. 
Five-micrometer sections were stained with hematoxylin-eosin to determine the number of neutrophils and the degree of necrosis. Neutrophils were counted in 50 nonconsecutive $400 \times$ histological power fields in liver sections, to a depth of $0.5 \mathrm{~cm}$ below the surface, so that this number would be comparable with liver surface chemiluminescence. N eutrophils were identified by their size (10-12 $\mu \mathrm{m})$ and their segmented nuclei. Only neutrophils that were present within sinusoids or had extravasated into the tissue were counted. Neutrophils in necrotic areas were not counted; the number was expressed as the average number of neutrophils per histological power field.

Samples of nonischemic and ischemic liver were taken 4 hours after reperfusion from rats treated with sterile $0.9 \% \mathrm{NaCl}$ solution, then they were fixed with $2.5 \%$ glutaraldehyde solution in $0.1 \mathrm{~mol} / \mathrm{L}$ sodium phosphate buffer $(\mathrm{pH} 7.4)$ for 3 hours at $4^{\circ} \mathrm{C}$, postfixed in a $2 \%$ osmium tetroxide solution, dehydrated in graded ethanol solutions, and embedded in Epon-Aral dite. Ultrathin sections stained with uranyl acetate and lead citrate were examined through a 410 Philips transmission electron microscope (Philips Electronic Instruments, Inc., Eindhoven, Holland) with an $80-\mathrm{kV}$ acceleration voltage. The 4-hour time of reperfusion was chosen to avoid the interference of cell debris in the examination of the possible spatial relationship between hepatocytes and neutrophils.

Necrosis was graded using an arbitrary scale through the evaluation of 15 nonconsecutive acini as follows: 1 point, scattered necrotic hepatocytes distributed in the acinus; 2 points, presence of a focus of necrotic hepatocytes; 3 points, presence of 2 or more foci of necrotic hepatocytes; 4 points, total necrosis of the acinus ( panacinar necrosis). The degree of necrosis of each liver sample was obtained by summing the points assigned to the individual acini. A maximum of 60 points was possible.

Neutrophil Isolation and Spectral Analysis. Human neutrophils were isolated by conventional procedures and suspended in $145 \mathrm{mmol} / \mathrm{L}$

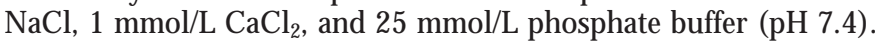
Phorbol 12-myristate 13-acetate (PMA) $(0.15 \mu \mathrm{g} / \mathrm{mL})$ was added to $3 \times 10^{6} / \mathrm{mL}$ cell aliquots, ${ }^{29}$ and spectral analysis of activated neutrophil chemiluminescence was performed with cut-off Kodak Wratten filters. ${ }^{26}$

Statistical Analysis. Tables and figures report means of four experiments \pm SEM . Data were analyzed statistically by factorial ANOVA, followed by the Bonferroni test for other comparisons. Differences between $145-\mathrm{mmol} / \mathrm{L} \mathrm{NaCl}$ - and $\mathrm{GdCl}_{3}$-treated rats were analyzed by the unpaired two-tailed Student $t$ test. Regression output analysis between determinations was performed using the Spearman correlation coefficient.

Chemicals. Hydrogen peroxide, $\mathrm{GdCl}_{3}$, o-dianisidine-dihydrochloride, and hexadecyl-trimethyl ammonium were from Sigma
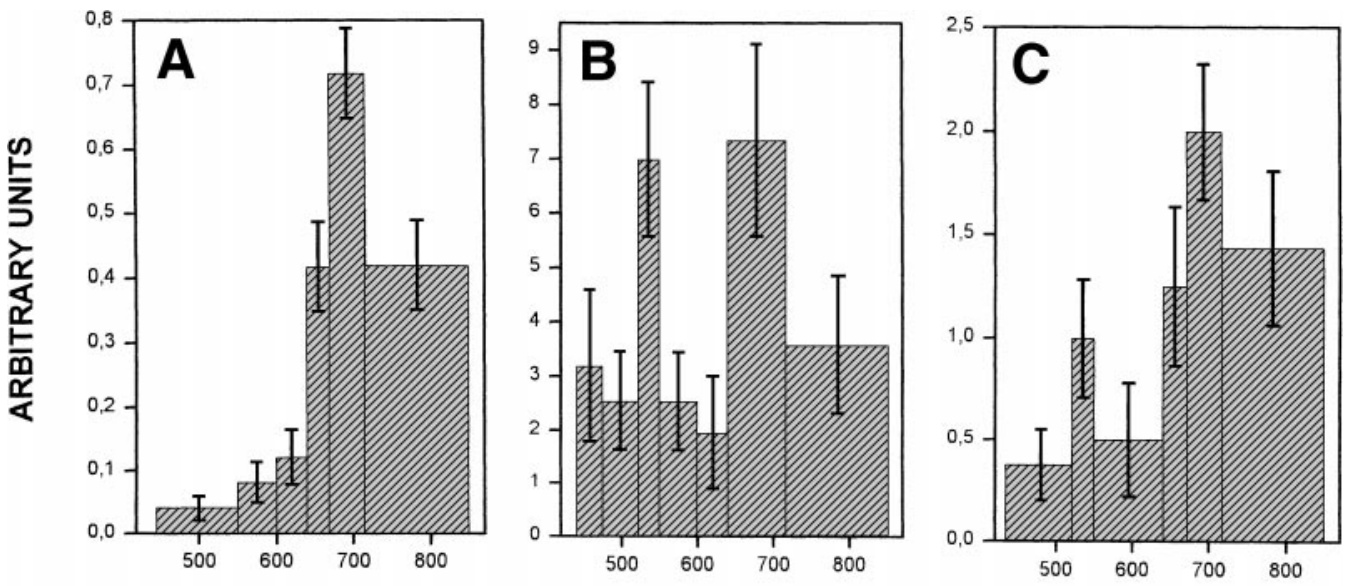

WAVELENGTH $(\mathrm{nm})$

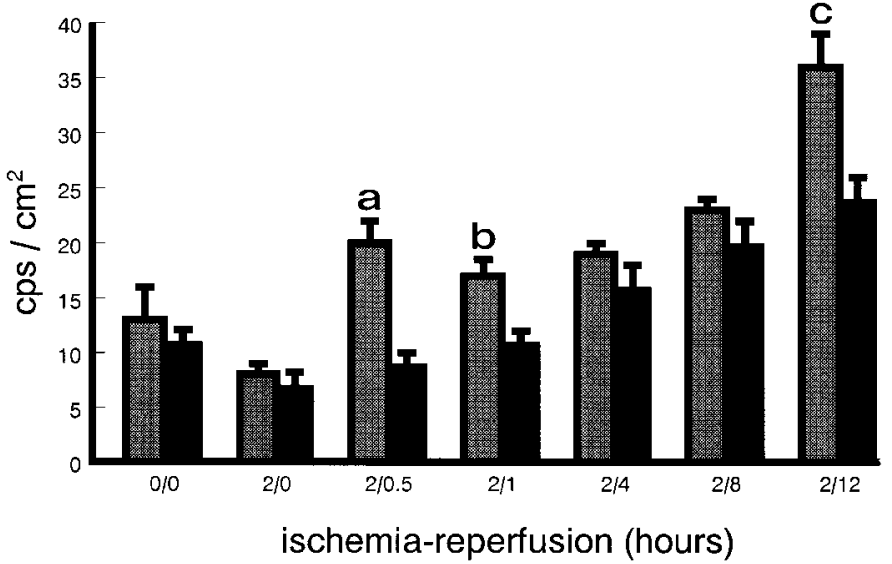

FIG. 3. Rat liver chemiluminescence during ischemia-reperfusion and effect of $\mathrm{GdCl}_{3}$ pretreatment. Experimental details are given in M aterials and Methods. Spontaneous chemiluminescence before the cycle of ischemiareperfusion (0/0); after 2 hours of ischemia (2/0); after 2 hours ischemia and 0.5 hours reperfusion (2/0.5); after 2 hours ischemia and 1 hour reperfusion (2/1); after 2 hours of ischemia and 4 hours of reperfusion (2/4); after 2 hours of ischemia and 8 hours of reperfusion (2/8); and after 2 hours of ischemia and 12 hours of reperfusion (2/12). a, significantly different from $2 / 0.5 \mathrm{GdCl}_{3}$ ischemic lobes $(P<.01)$; $b$, significantly different from $2 / 1 \mathrm{GdCl}_{3}$ ischemic lobes $(P<.05) ; C$, significantly different from $2 / 12 \mathrm{GdCl}_{3}$ ischemic lobes $(\mathrm{P}<.01)$. (四), Rats and saline; $(\mathbf{\square})$, rats and $\mathrm{GdCl}_{3}$.

Chemicals Co. (St. Louis, MO). Other reagents were of analytical grade.

\section{RESULTS}

Liver Surface Chemiluminescence as Measurement of Oxidative Stress During Ischemia-Reperfusion. The spontaneous surface chemiluminescence of the liver in situ, before ischemiareperfusion, was $12 \pm 2 \mathrm{cps} / \mathrm{cm}^{2}$, which is consistent with a steady-state concentration of ${ }^{1} \mathrm{O}_{2}$ of about $10^{-16} \mathrm{~mol} / \mathrm{L} .{ }^{30}$ In the first oxidative phase after reoxygenation, liver chemiluminescence increased markedly to 2.6 times the initial spontaneous chemiluminescence as a transient burst, with maximal emission at 30 minutes and a decline 60 minutes after reperfusion (Fig. 2). Increased chemiluminescence directly indicates an increased concentration of ${ }^{1} \mathrm{O}_{2}$ and other excited
FIG. 4. Spectral distribution of chemiluminescence of rat liver and stimulated neutrophils. (A) Spontaneous rat liver chemiluminescence. (B) Chemiluminescence of neutrophils $\left(3 \times 10^{6}\right.$ cell $\left.\mathrm{s} / \mathrm{mL}\right)$ suspended in $145 \mathrm{mmol} / \mathrm{L} \mathrm{NaCl}, 1 \mathrm{mmol} / \mathrm{L}$ $\mathrm{CaCl}_{2}, 25 \mathrm{mmol} / \mathrm{L}$ phosphate buffer (pH 7.4) stimulated with $0.15 \mu \mathrm{g} / \mathrm{mL}$ PMA. (C) Chemiluminescence of rat liver subjected to 2 hours' ischemia and 12 hours' reperfusion. 
species, and indirectly indicates both a higher concentration of oxidative free radicals and an increased rate of free radical reactions in the liver. The increased steady-state concentrations of ${ }^{1} \mathrm{O}_{2}$, other excited species, and oxidizing free radicals constitute the chemicals basis of biological oxidative stress. ${ }^{6}$ Liver chemiluminescence increased again in the second oxidative phase after blood reflow, which began after 4 hours of reperfusion (Fig. 2) and continued for up to 12 hours of reperfusion (Fig. 2). Treatment with $\mathrm{GdCl}_{3}$ abolished the first oxidative phase and partially decreased photoemission during the second phase, after 12 hours of reperfusion (Fig. 3).

Spectral analysis of spontaneous liver chemiluminescence (Fig. 4A) shows a main broad emission band in the red region, between $640 \mathrm{~nm}$ and the unresolved 715- to 850-nm band, which is consistent with ${ }^{1} \mathrm{O}_{2}$ dimol emission at 634 and $711 \mathrm{~nm} .{ }^{22}$ In the interval of 440 to $640 \mathrm{~nm}$, the emission of control liver, measured in arbitrary units, is very low (Fig. 4A). Spectral analysis of the chemiluminescence of PMAactivated neutrophils (Fig. 4B), in addition to a much more intense red emission band (640-715 nm), shows a second broad band with maximum emission at 520 to $535 \mathrm{~nm}$ and emission in the blue (440-520 nm) and yellow-green (535$640 \mathrm{~nm}$ ) wavelengths. ${ }^{31}$ The blue emission is consistent with the production of excited carbonyl compounds, and the 520to $535-\mathrm{nm}$ band is consistent with the emission from a dioxetane intermediate compound type. ${ }^{32}$ Spectral analysis of

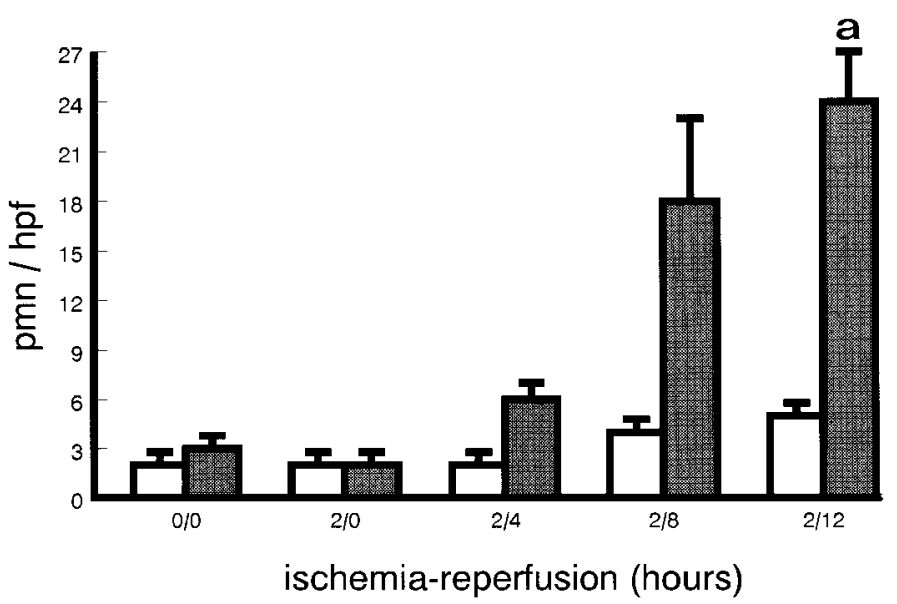

FIG. 5. Number of neutrophils in the liver during the late reperfusion phase (pmn/hpf):number of neutrophils per histological power field. Before ischemia-reperfusion cycle (0/0); after 2 hours of ischemia (2/0); after 2 hours of ischemia and 4 hours of reperfusion (2/4); after 2 hours of ischemia and 8 hours of reperfusion (2/8); and after 2 hours of ischemia and 12 hours of reperfusion (2/12). a, significantly different from $0 / 0,2 / 0$, and $2 / 4$ ischemic lobes $(\mathrm{P}<.05) .(\square)$, Nonischemic lobes; $(\square)$, ischemic lobe.

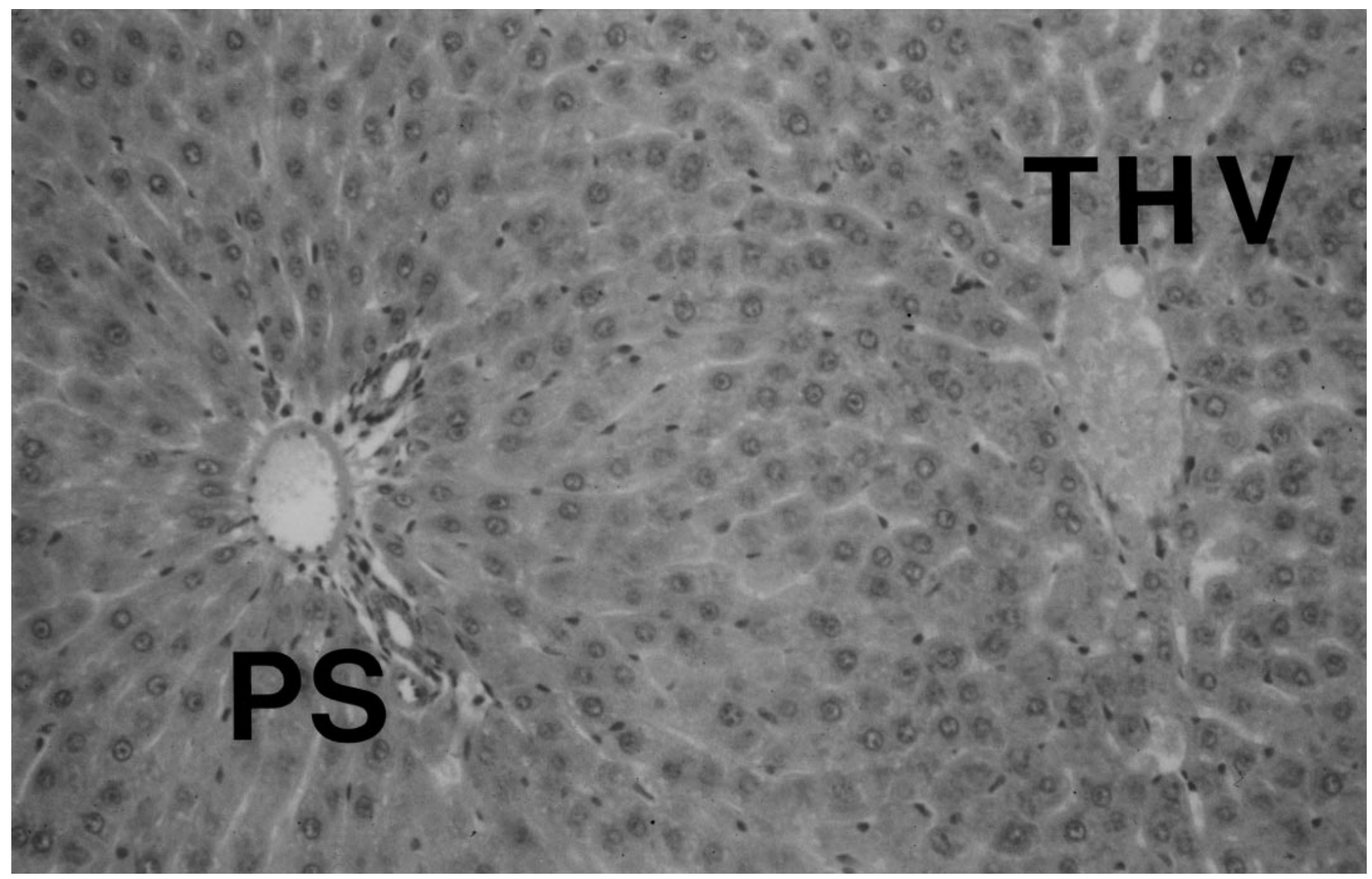

FIG. 6. Nonischemic lobes (used as internal control) after a complete cycle of ischemia-reperfusion. PS: portal space, where branches of portal vein, hepatic artery, and intrahepatic biliary tree are visible; THV, terminal hepatic venule. The hepatic cords are correctly distributed in fashion in both affluent and effluent vascular structures. 


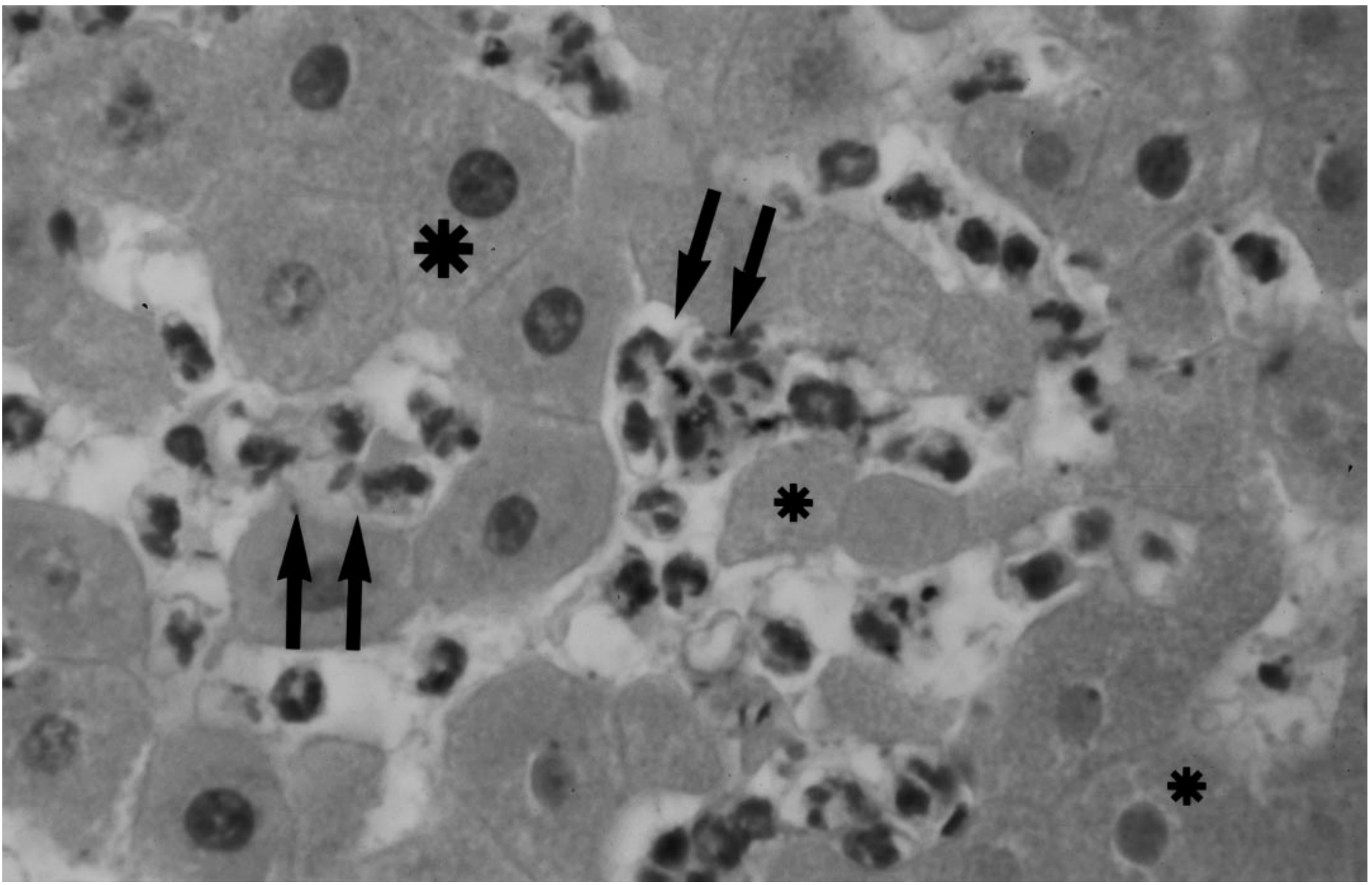

FIG. 7. Neutrophil accumulation in the ischemic lobes after 12 hours of reperfusion. The arrows indicate dilated sinusoids plugged by neutrophils. Hepatocytes of relatively normal appearance are visible (large asterisk), as well as other adjacent altered cells (small asterisks).
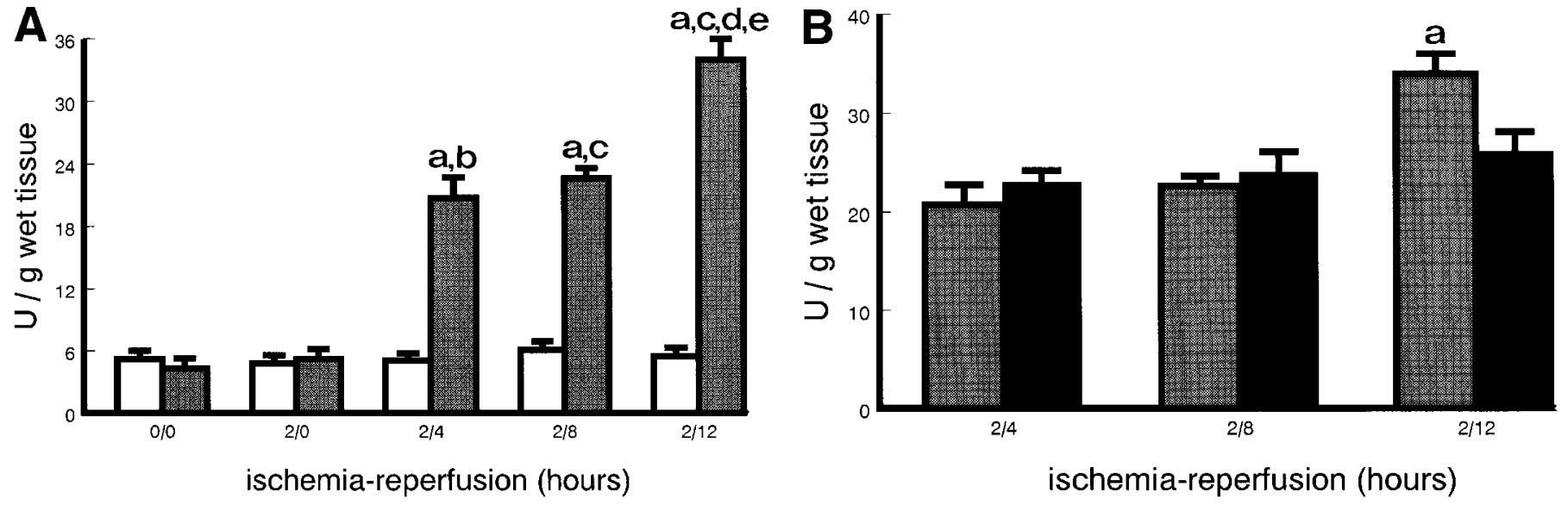

FIG. 8. (A) Rat liver activity of the myeloperoxidase enzyme during ischemia-reperfusion. Experimental details are given in Materials and Methods. Activity of myeloperoxidase before the ischemia-reperfusion cycle (0/0); after 2 hours of ischemia (2/0); after 2 hours of ischemia and 4 hours of reperfusion (2/4); after 2 hours of ischemia and 8 hours of reperfusion (2/8); and after 2 hours of ischemia and 12 hours of reperfusion. a, significantly different from $0 / 0$ ischemic lobes $(P<.001) ; b$, significantly different from $2 / 0$ ischemic lobes $(P<.01)$; $c$, significantly different from $2 / 0$ ischemic lobes $(P<.001)$; $d$, significantly different from $2 / 4$ ischemic lobes $(P<.001)$; e, significantly different from $2 / 8$ ischemic lobes $(P<.01)$. ( $\square$ ), Nonischemic lobes; $(\square)$, ischemic lobe. (B) Rat liver activity of the myeloperoxidase enzyme during the late reperfusion phase and effect of $\mathrm{GdCl}_{3}$ pretreatment. M yel operoxidase activity after 2 hours of ischemia and 4 hours of reperfusion (2/4); after 2 hours of ischemia and 8 hours of reperfusion (2/8); and after 2 hours of ischemia and 12 hours of reperfusion (2/12). a, significantly different from $2 / 12 \mathrm{GdCl}_{3}$ ischemic lobes. (四), Rats and saline; ( $\left.\mathbf{\square}\right)$, rats and $\mathrm{GdCl}_{3}$. 


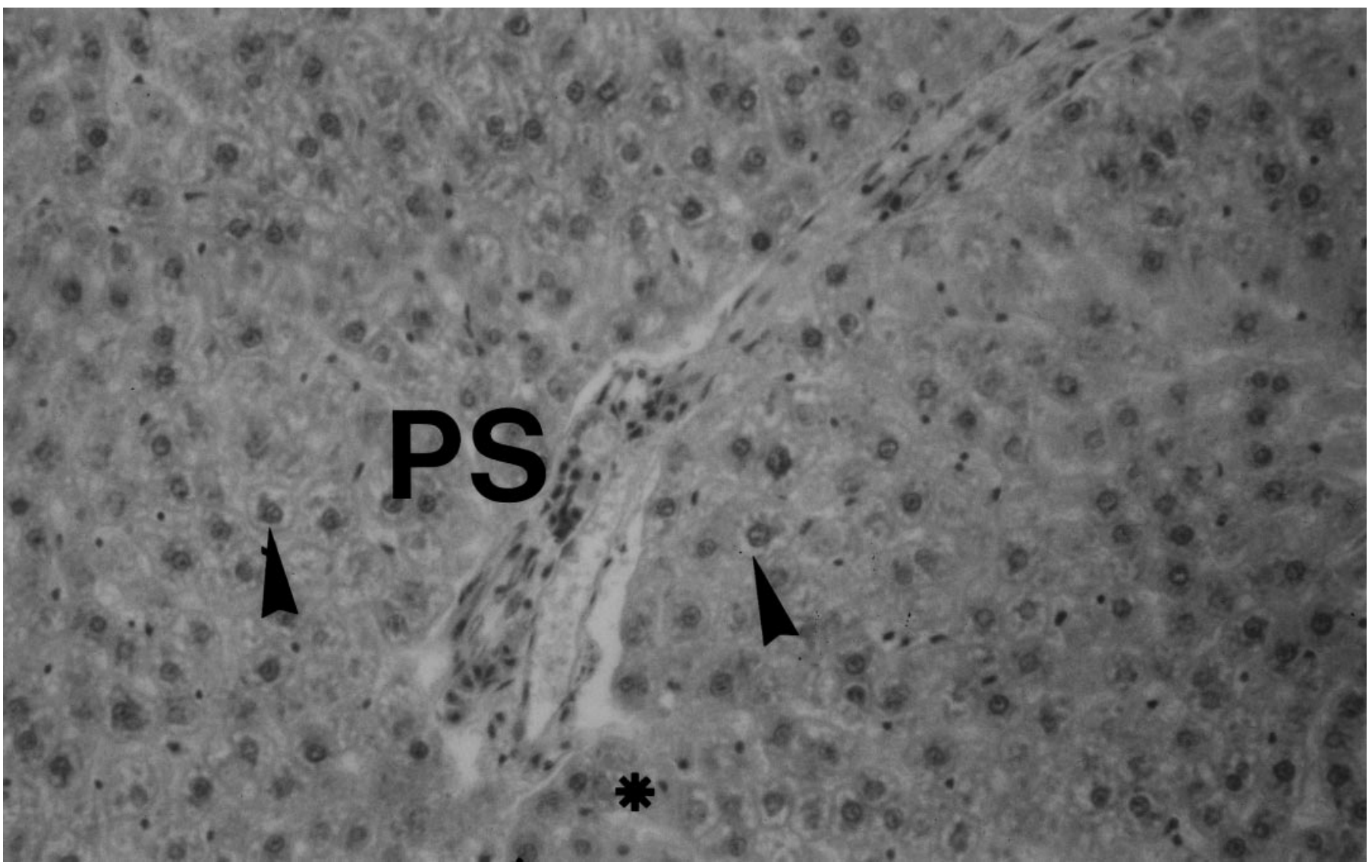

FIG. 9. Morphology of the acinus after 2 hours of ischemia. PS, A portal space where vascular and biliary components appear to be well preserved. The arrows indicate hepatocytes with different degree of swelling, while the asterisk indicates scattered necrotic hepatocytes.

the chemiluminescence of rat liver after 2-hour ischemia and 12-hour reperfusion (Fig. 4C) showed a significantly increased red emission at 640 to $715 \mathrm{~nm}$ with respect to control liver and a band at 520 to $535 \mathrm{~nm}$ not present in the control tissue; the latter band indicated the participation of activated neutrophils in organ chemiluminescence.

The Inflammatory Response as an Amplification Mechanism of Oxidative Damage to Parenchymal Cells. The number of neutrophils in the liver increased progressively in the postischemic lobes during the 4- to 12-hour period after blood reflow, showing approximately a 6 -fold increase 12 hours after declamping (Fig. 5), while there was no change in the neutrophil number (3-6 per histological power field) in the nonischemic lobes. The latter lobes showed normal histology at the light-microscopic observation performed at the end of the ischemia-reperfusion cycle (Fig. 6). On the other hand, in those lobes subjected to ischemia and reperfusion, some of the numerous neutrophils present appeared to reach close contact with the surface of hepatocytes (Fig. 7).

Liver myeloperoxidase activity in the group of rats treated with $145 \mathrm{mmol} / \mathrm{L} \mathrm{NaCl}$ solution, compared with that in nonischemic tissue (liver before ischemia and controls: $5.2 \pm$ $0.5 \mathrm{U} / \mathrm{g}$ wet tissue), was significantly higher at all experimental time points of the late reperfusion phase, reaching 6.5 times above control values after 12 hours of reflow (Fig. 8A). On the contrary, in the liver of rats treated with $\mathrm{GdCl}_{3}$, myeloperoxidase activity increased after 4 hours of reperfu- sion but without any further rise during the late reperfusion phase (Fig. 8B).

Hepatocellular Damage D uring Reperfusion as a C onsequence of Neutrophil Infiltration. The liver acinar structure was mostly preserved after 2 hours of ischemia. However, there were some foci of hepatic cord disarrangement as a result of the presence of hepatocytes that were swollen to varying extents and of collapsed sinusoids, mainly in the periportal and midzonal regions of the acinus. Scattered necrotic hepatocytes were also observed (Fig. 9). During the late phase of reperfusion, yellowish-green zones appeared over the congested hepatic surface, corresponding histologically to severe hepatocellular necrosis, and mainly disposed around the portal triads. This necrotic zonal distribution was parallel to neutrophil infiltration (Fig. 10 and Table 1).

Assessed by electron microscopy, sinusoidal spaces appeared dilated, denuded, and containing several neutrophils. In some fields, neutrophils appeared in close contact with injured hepatocytes, without interposition of sinusoidal lining (Figs. 11 and 12). On the contrary, the nonischemic lobes showed a normal cytoarchitecture with regular appearance and mutual relationship of intracellular organelles (Fig. 13).

Correlation of the Morphometric and Biochemical Parameters of Inflammatory Liver Injury After Reperfusion. Regression analysis was performed for: 1) the number of neutrophils counted in the tissue; 2) homogenate myeloperoxidase activity; 3 ) in situ liver chemiluminescence; and 4) the necrotic score of the 


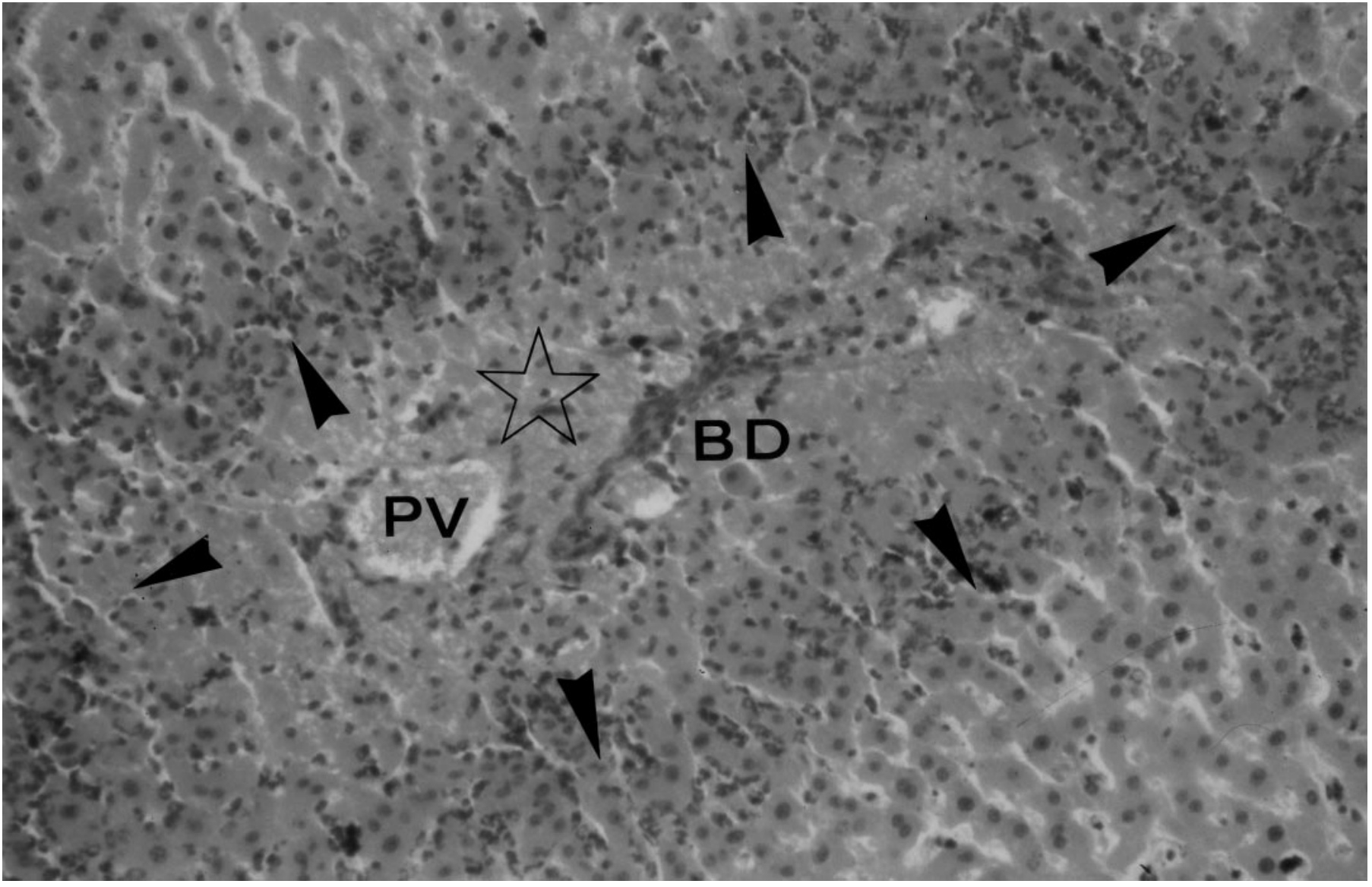

FIG. 10. Inflammatory response and hepatocellular necrosis after 12 hours of reperfusion. The star indicates a necrotic portal space where branches of the portal vein (PV) and intrahepatic biliary ducts (BD) are still recognizable. N eutrophils appear to leave the portal space in a centrifugal way (arrowheads). Once in the acinus, they appear to induce an interface of hepatocellular necrosis.

liver acini. The linear correlations between each pair of variables, with high statistical significance, support a basic role for neutrophils in postischemic liver injury (Table 2).

\section{DISCUSSION}

Liver injury induced by ischemia and reperfusion is a common event, which frequently follows circulatory shock with resuscitation, as well as many types of liver surgery, including transplantation and tumor resection.

Contributing to oxidative stress of the early phase of

TABLE 1. Liver Necrosis After Ischemia-Reperfusion

\begin{tabular}{|c|c|}
\hline Condition & Necrosis Score \\
\hline Control (nonischemia) & 0 \\
\hline Ischemia ( 2 hours) & $13.5 \pm 0.6 *$ \\
\hline + reperfusion (4 hours) & $30.3 \pm 3.0 \dagger \neq$ \\
\hline + reperfusion (8 hours) & $40.3 \pm 2.2 \dagger, \S$ \\
\hline +reperfusion (12 hours) & $51.3 \pm 0.7 \dagger \S\|\|$, \\
\hline
\end{tabular}

*Significantly different from control $(\mathrm{P}<.05)$.

†Significantly different from control $(P<.001)$

$\ddagger$ Significantly different from ischemic lobes $(P<.01)$.

$\S$ Significantly different from ischemic lobes $(P<.001)$.

$\|$ Significantly different from 4 hours reperfused lobes $(P<.01)$.

ISignificantly different from 8 hours reperfused lobes $(P<.05)$. reperfusion, as assessed by organ chemiluminescence, is the production of reactive oxygen species as well as of $\mathrm{NO}$ by Kupffer cells,7,18,19 which can diffuse to hepatocytes and endothelial cells and cause mitochondrial dysfunction. ${ }^{18} \mathrm{NO}$ markedly inhibits cytochrome oxidase activity and mitochondrial respiration, and increases the mitochondrial production of superoxide radicals and $\mathrm{H}_{2} \mathrm{O}_{2} \cdot{ }^{33,34}$ Inhibition of the Kupffer cells with gadolinium chloride leads to disappearance of the oxidative stress in the early reperfusion phase. Accordingly, it seems that gadolinium blocks not only phagocytosis, ${ }^{35}$ but al so $\mathrm{NO}$ production, the latter being inferred from the lack of a chemiluminescence burst after reflow.

The accumulation of neutrophils during the late phase of liver reperfusion is mediated by the local generation of chemotactic agents, which regulate neutrophil migration from the vascular compartment to the parenchymal cells. In this sense, there is a large body of evidence from different models of hepatic inflammation to indicate that oxygen free radicals play a central role in promoting neutrophil infiltration in the liver. For example, it has been claimed that the release by the postischemic liver of platelet activating factor and leukotriene $B_{4}$, two potent agents that promote neutrophil chemotaxis, depends on the generation of oxygen radicals by the cells. ${ }^{9,10,20,36-39}$ M oreover, it has recently been suggested that hepatocytes, in response to an agonist stimu- 


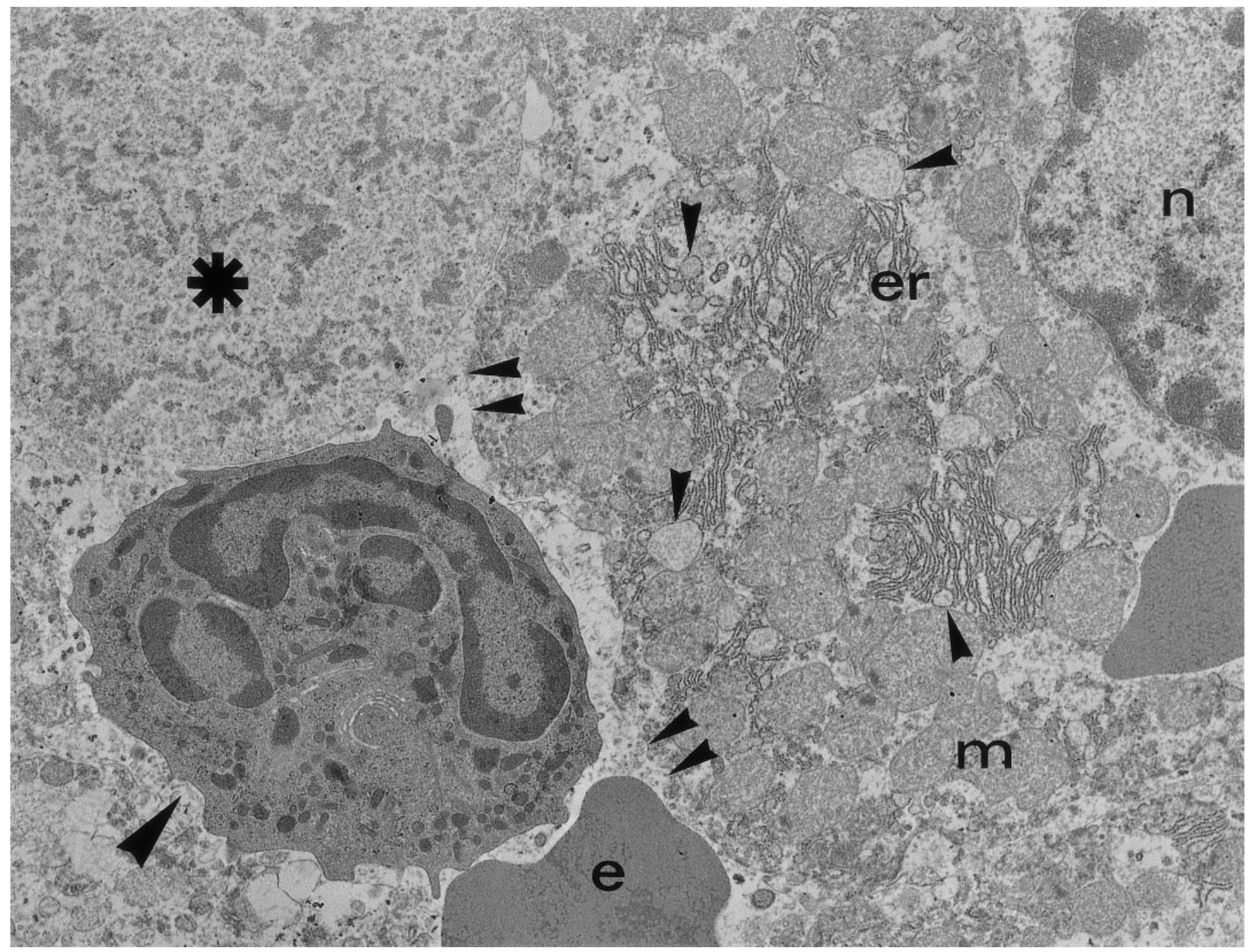

FIG. 11. Electron micrograph of ischemic lobe after 4 hours of reperfusion. Sinusoids are denuded, dilated, and contain neutrophils, cell debris, and erythrocytes. The absence of a sinusoidal barrier appears to facilitate the close contact between hepatocytes and neutrophils (large arrowhead). U Itrastructural indices of hepatocyte damage are: dilation of endoplasmic reticulum (single small arrowheads), swelling of cytosol, presence of autophagic vacuoles, focal lysis of plasma membrane (double small arrowheads), and marked swelling of mitochondrial inner compartment. The large asterisk indicates a bleb projected to the sinusoidal lumen. e, erythrocyte; er, endoplasmic reticulum; $m$, mitochondria. (Originall magnification $\times 12,320$.)

lus most probably released by activated Kupffer cells, such as tumor necrosis factor $\alpha$ and interleukin-1, initiate and amplify an acute inflammatory response through the regulated expression and secretion of specific proinflammatory cytokines, e.g., interleukin-8 and neutrophil activating protein78.40

The activation of intact neutrophils is accompanied by the production of reactive species such as superoxide radical 29,41 and NO,29,42 as well as by light emission. ${ }^{42}$ Because the thickness of liver tissue that decreases transmittance of light in the 650- to 700-nm wavelength band to one half is about $0.5 \mathrm{~cm}, 21$ activation of neutrophils located at less than $0.5 \mathrm{~cm}$ below the liver surface will be detected by organ surface photoemission. Organ surface chemiluminescence thus becomes an assay for organ inflammation in situ. The positive correlation between the number of infiltrated neutrophils counted in the liver parenchyma with 1) in situ liver chemiluminescence, and 2) liver necrosis indicates that the neutrophils are activated in reperfused hepatic tissue and are, at least in part, responsible for irreversible tissue damage. The observed alterations of sinusoidal spaces with even contact between the neutrophils and damaged hepatocytes (Figs. 11 and 12) confirm this hypothesis.

However, Kupffer cells still appear to contribute to the inflammatory response in the later phase of reperfusion; as shown in Figs. 3 and 8B, both surface chemiluminescence and tissue activity of myeloperoxidase at 12 hours of reperfusion were down-regulated by $\mathrm{GdCl}_{3}$ treatment. Kupffer cells may influence the later outcome of the inflammatory response through the release of by-products that attract and activate neutrophils.

There are several ways by which the activated neutrophils might induce tissue injury: these include activation of NADPH oxidase $e^{41,43}$ and NO synthase, ${ }^{29,42}$ and release of products of arachidonic acid metabolism (eicosanoids) and proteolytic enzymes (elastase, metalloproteinases, etc.) ${ }^{44}$ W hen neutrophils infiltrated into the liver parenchyma are activated, membrane-bound nicotinamide adenine dinucleotide phos- 


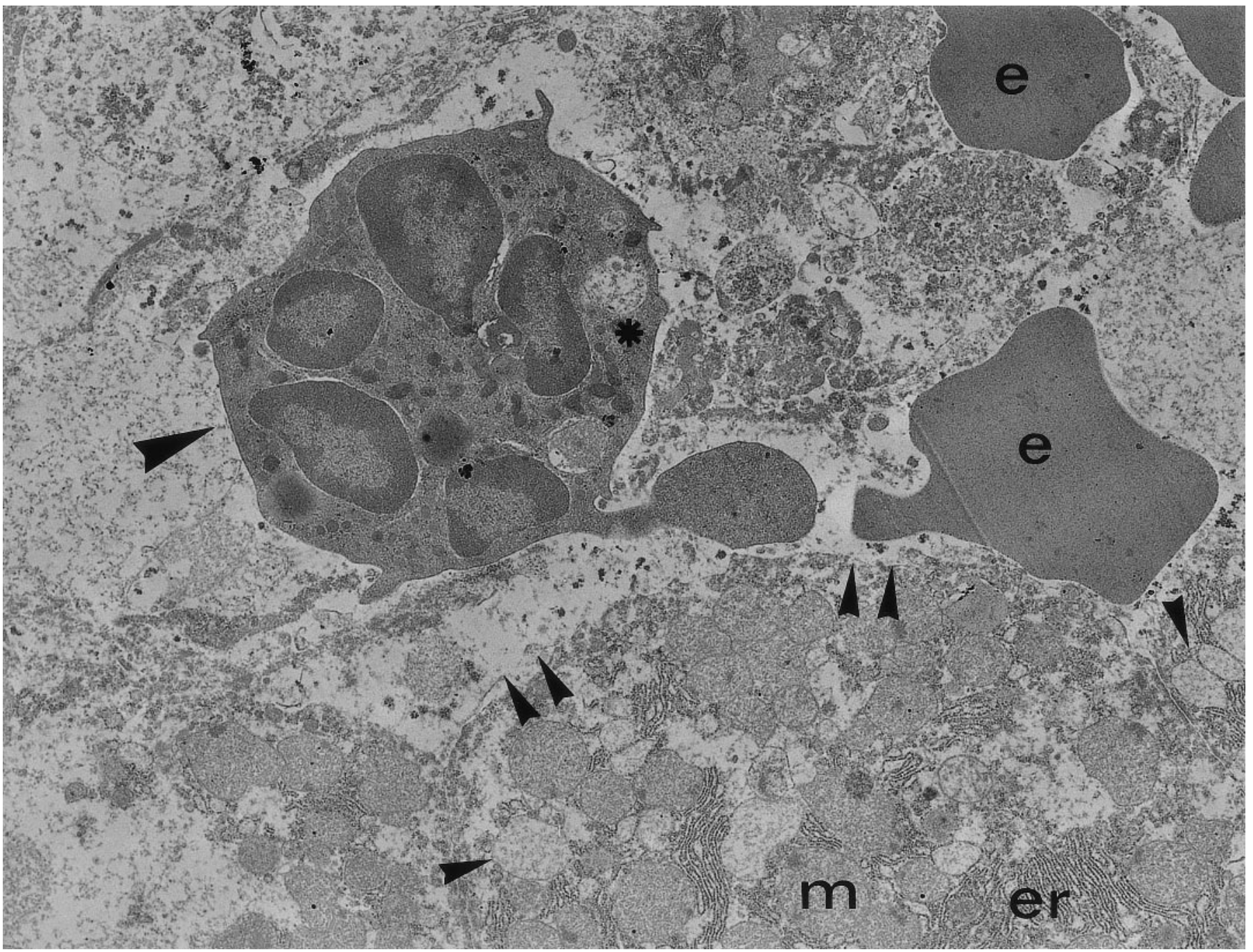

FIG. 12. Electron micrograph of ischemic lobe after 4 hours of reperfusion. Neutrophil is emitting pseudopodia toward hepatocytes (large arrowhead) Small asterisk indicates vacuoles of phagocytosis inside the neutrophil. Other symbols are as indicated in the Fig. 11. (Original magnification $\times 12,320$.)

phate, reduced form (NADPH)-oxidase ${ }^{41}$ and NO synthase 29,42 initiate rapid oxygen uptake, known as the respiratoryburst, 41,44 in which superoxide anion radicals $\left(\mathrm{O}_{2}^{-}\right)$and $\mathrm{NO}$ are produced in near-equimolar quantities 29,42 and released into the extracellular space. The released primary products, $\mathrm{O}_{2}^{-}$and $\mathrm{NO}$, react to produce $\mathrm{H}_{2} \mathrm{O}_{2}$ and peroxynitrite $\left(\mathrm{ON} \mathrm{OO}^{-}\right) .{ }^{45}$ In the presence of superoxide dismutase in the extracellular space, more $\mathrm{H}_{2} \mathrm{O}_{2}$ is formed; in its absence, more $\mathrm{ONOO}^{-}$is formed. Both $\mathrm{H}_{2} \mathrm{O}_{2}$ and $\mathrm{ONOO}^{-}$are highly cytotoxic, the former being a direct powerful oxidant, and the latter acting indirectly, yielding the highly reactive hydroxyl radical (HO) after homolysis by reaction with $\mathrm{Fe}^{2+}$. It is well known that the oxidants released by neutrophils during the respiratory burst effectively produce cell and tissue damage during the inflammatory response. ${ }^{43,44}$ Because the process is mediated by reactive species, cytotoxicity will be stronger when the chemoattracted neutrophils become activated and approach endothelial and even parenchymal cells.

Activated neutrophils produce ${ }^{1} \mathrm{O}_{2}$ that is detected chemically or by chemiluminescence. ${ }^{46-48}{ }^{1} \mathrm{O}_{2}$ is an excited state of molecular oxygen with a half-life of about 2 to 3 microseconds that yields one photon from the molecular collision of two ${ }^{1} \mathrm{O}_{2}$ molecules $\left(2{ }^{1} \mathrm{O}_{2} \rightarrow 2 \mathrm{O}_{2}+\mathrm{hv}\right)$. The photon given off by the dimol emission of ${ }^{1} \mathrm{O}_{2}$ affords the basis of the chemiluminescence assay ${ }^{21-23}$ used in this study to monitor oxidative stress in the liver in situ. Three chemical reactions, probably occurring simultaneously during neutrophil activation, can be indicated as sources of ${ }^{1} \mathrm{O}_{2}$. First, membrane lipid oxidation, caused by neutrophil oxidative burst, generates hydroperoxyl radicals (ROO), which after bimolecular collisions yield ${ }^{1} \mathrm{O}_{2} \cdot{ }^{21-23}$ Second, hypochlorous acid is formed in the myeloperoxidase-catalyzed oxidation of chloride anion by hydrogen peroxide $\left(\mathrm{H}_{2} \mathrm{O}_{2}+\mathrm{Cl}^{-} \rightarrow\right.$ $\mathrm{HOCl}+\mathrm{HO}^{-},{ }^{47}$ and ${ }^{1} \mathrm{O}_{2}$ is formed in the reaction of hypochlorous acid with hydrogen peroxide $\left(\mathrm{H}_{2} \mathrm{O}_{2}+\mathrm{HOCl} \rightarrow\right.$ $\left.\mathrm{H}_{2} \mathrm{O}+\mathrm{Cl}+{ }^{1} \mathrm{O}_{2}\right) .47,48$ Finally, it has recently been recognized that $\mathrm{ONOO}^{-}$reacts with $\mathrm{H}_{2} \mathrm{O}_{2}$ to yield ${ }^{1} \mathrm{O}_{2}{ }^{49}$

The results of this study provide substantial evidence that Kupffer cell activation and neutrophil recruitment and activation play a central role in building up reperfusion damage in 


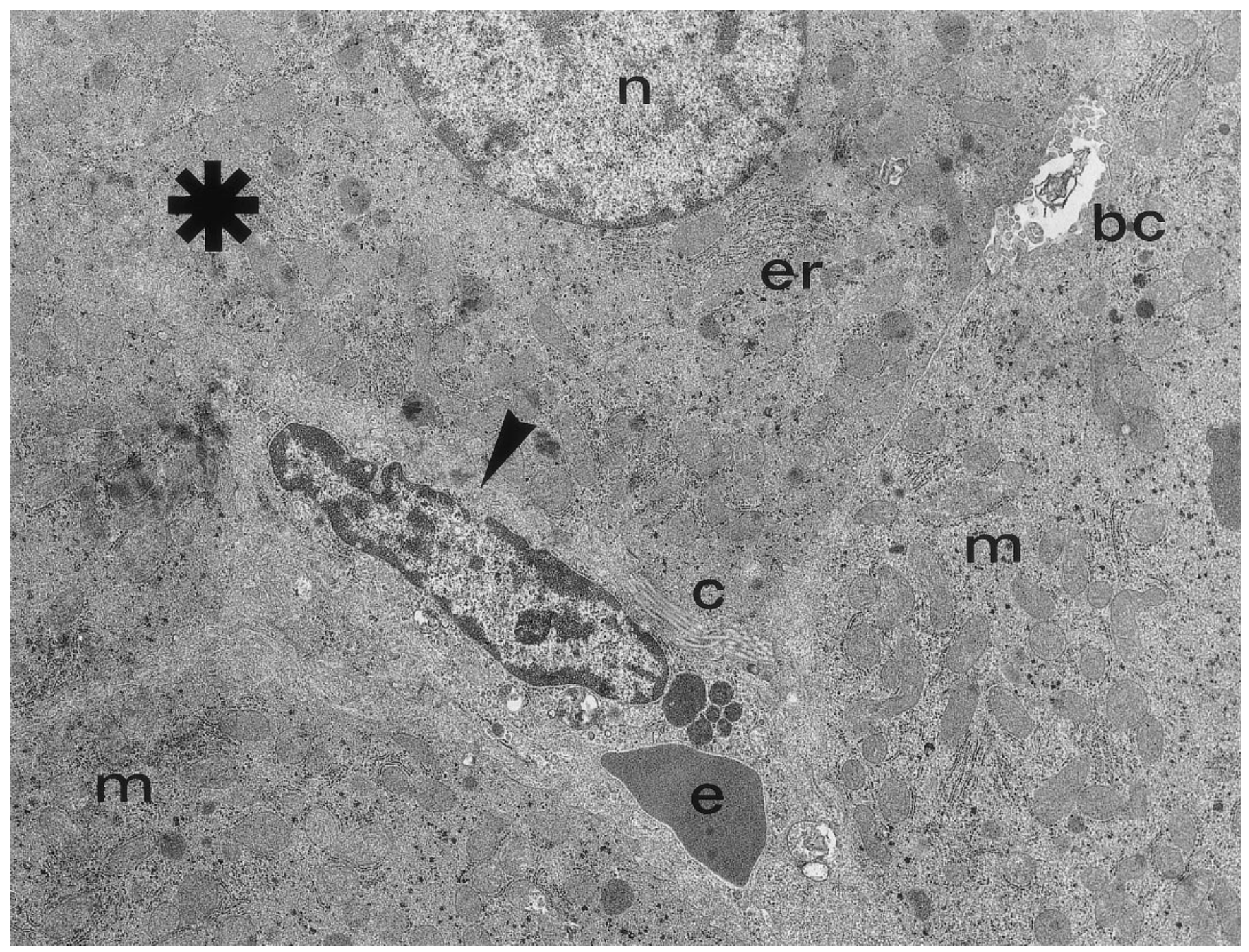

FIG. 13. Electron micrograph of nonischemic lobe after 4 hours of reperfusion. Sinusoidal endothelial cells and surrounding hepatocytes were normal in appearance. Scattered red cells (e) were evident into the sinusoidal lumen. The arrowhead indicates a sinusoidal endothelial cell. The asterisk indicates mutual relationships of intracellular organelles. bc, bile canaliculi; c, subendothelial collagen. Other markers as in Figs. 11 and 12 . (Original magnification $\times 8,400$.)

the liver. In addition, they point to surface chemiluminescence as a useful technique to examine the temporal relationship between evolution of warm ischemia-reperfusion injury and phagocyte activation and recruitment in situ and in vivo.

TABLE 2. Linear Correlation Among the Parameters Measured During the Ischemia-Reperfusion C ycle

\begin{tabular}{|c|c|c|c|}
\hline Parameters & \multicolumn{2}{|c|}{ Correlation C oefficient ( $r$ ) } & Significance \\
\hline CL/PMN & \multicolumn{2}{|c|}{.99} & $\mathrm{P}<.0001$ \\
\hline CL/MPO & \multicolumn{2}{|c|}{.99} & $\mathrm{P}<.0001$ \\
\hline $\mathrm{PMN} / \mathrm{MPO}$ & \multicolumn{2}{|c|}{.95} & $P<.05$ \\
\hline \multirow[t]{3}{*}{ Necrosis/PMN } & & & $P<.03$ \\
\hline & \multicolumn{3}{|c|}{ Regression Equations } \\
\hline & Slope & y Intercept & x Intercept \\
\hline CL/PMN & $913.02 \pm 1.63$ & $-756.72 \pm 2.99$ & 0.83 \\
\hline CL/MPO & $17.35 \pm 5.90$ & $-9.22 \pm 0.11$ & 0.53 \\
\hline PMN/MPO & $1.75 \pm 4.06$ & $6.36 \pm 4.03$ & -363.80 \\
\hline Necrosis/PMN & $0.42 \pm 0.11$ & $-0.63 \pm 3.70$ & 1.47 \\
\hline
\end{tabular}

Abbreviations: $\mathrm{CL}$, chemiluminescence; PMN, number of neutrophils; MPO, myeloperoxidase tissue activity.

\section{REFERENCES}

1. Parks DA, Bulckley GB, Granger DN. Role of oxygen free radical in shock, ischemia, and organ preservation. Surgery 1983;94:428-432.

2. Atalla SL, Toledo-Pereyra LH, Mac Kenzie GH, Cederna JP. Influence of oxygen-derived free radical scavengers on ischemic livers. Transplantation 1985;40:584-590.

3. Adkinson D, Hoellwarth ME, Benoit JN, Parks DA, Mc Cord JM, Granger $D N$. Role of the free radicals in ischemia-reperfusion injury to the liver. Acta Physiol Scand Suppl 1986;548:101-107.

4. Jaeschke H, Farhood A. Neutrophil and Kupffer cell induced oxidant stress and ischemia-reperfusion injury in rat liver. Am J Physiol 1991;260:G335-G342.

5. Jaeschke $H$, Farhood $A$. N eutrophils contribute to ischemia/reperfusion injury in rat liver in vivo. FASEB J, 1990;4:3355-3359.

6. Gonzàlez Flecha B, Cutrìn JC, Boveris A. Time course and mechanisms of oxidative stress and tissue damage in rat liver subjected to in vivo ischemia-reperfusion. J Clin Invest 1993;91:456-464.

7. Cutrìn JC, Llesuy S, Boveris A. Primary role of Kupffer cell-hepatocyte communication in the expression of oxidative stress in the postischaemic liver. Cell Biochem Function 1998;16:65-72.

8. Gonzàlez Flecha B, Reides C, Cutrìn JC, Llesuy SF, Boveris A. Oxidative stress produced by suprahepatic occlusion and reperfusion. HePATOLOGY 1993;18:881-889.

9. Mawet E, Shiratori Y, Hikiba Y, Takada H, Yoshida H, Okano K, Komatsu 
$Y$, et al. Cytokine-induced neutrophil chemoattractant release from hepatocytes is modulated by Kupffer cells. HePATOLOGY 1996;23:353358.

10. Hisama N, Yamaguchi Y, Ishiko T, Miyanari N, Ichiguchi O, Goto M, Mori K, et al. Kupffer cell production of cytokine-induced neutrophil chemoattractant following ischemia/reperfusion injury in rats. HEPATOLOGY 1996;24:1193-1198.

11. Komatsu H, Koo A, Ghadishah E, Zeng H, Kuhlenkamp JF, Inoue M, Guth $\mathrm{PH}$, et al. Neutrophil accumulation in ischemic reperfused rat liver: evidence for a role for superoxide free radicals. Am J Physiol 1992;262:G669-G676.

12. Jaeschke H, Bautista AP, Spolarics Z, Spitzer JJ. Superoxide generation by Kupffer cells and priming of neutrophils during reperfusion after hepatic ischemia. Free Radic Res Commun 1991;15:277-284.

13. Jaeschke H, Farhood A, Bautista AP, Spolarics Z, Spitzer JJ, Smith CW. Functional inactivation of neutrophils with a Mac-1 (CD11b/CD18) monoclonal antibody protects against ischemia-reperfusion injury in rat liver. Hepatology 1993;17:915-923.

14. Lauterburg BH, Bilzer M. Oxidant stress and potentiation of ischemia/ reperfusion injury to the perfused rat liver by human polymorphonuclear leukocytes. J Hepatol 1994;20:473-477.

15. Suzuki S, Toledo-Pereyra LH, Rodrìguez FJ, Cejalvo D. Neutrophil infiltration as an important factor in liver ischemia and reperfusion injury. Transplantation 1993;55:1265-1272.

16. Langdale LA, Flaherty LC, Liggit HD, Harlam JM, Rice CL, Win RW. Neutrophils contribute to hepatic ischemia-reperfusion injury by a CD18-independent mechanism. J Leukoc Biol 1993;53:511-517.

17. Giulivi C, Poderoso JJ, Boveris A. Production of nitric oxide by mitochondria. J Biol Chem 1998;273:11038-11043.

18. Kurose I, Miura S, Higuchi H, Watanabe N, Kamegaya $Y$, Takaishi M, Tomita K, et al. Increased nitric oxide synthase activity as a cause of mitochondrial dysfunction in rat hepatocytes: role for tumor necrosis factor alpha. HEPATOLOGY 1996:24:1185-1192.

19. Stephenson K, Gupta A, Mustafa SB, Halff GA. Endothelin-stimulated nitric oxide production in the isolated Kupffer cell. J Surg Res 1997;73: 149-154.

20. Colleti LM, Kunkel SL, Walz A, Burdick MD, Kunkel RG, Wilke CA, Strieter RM. The role of cytokine networks in the local liver injury following hepatic ischemia/reperfusion in the rat. HePATOLOGY 1996;23: 506-514.

21. Boveris A, Cadenas E, Reiter R, Filipowski M, Nakase Y, Chance B. Organ chemiluminescence: noninvasive assay for oxidative radical reactions. Proc N atl Acad Sci U SA 1980;77:347-351.

22. Cadenas $\mathrm{E}$, Sies $\mathrm{H}$. Low-level chemiluminescence as an indicator of singlet molecular oxygen in biological systems. Methods Enzymol 1984;105:221-231.

23. Cadenas $E$, Boveris A, Chance B. Low-level chemiluminescence of biological systems. In: Pryor WA, ed. Free Radicals in Biology. N ew York: Academic Press, 1984:211-242.

24. Lores Arnaiz S, Llesuy S, Cutrìn JC, Boveris A. Oxidative stress by acute acetaminophen administration in mouse liver. Free Radic Biol Med 1995;19:303-310

25. Lores Arnaiz S, Travacio M, M onserrat AJ, Cutrìn JC, Llesuy S, Boveris A Chemiluminescence and antioxidant levels during peroxisome proliferation by fenofibrate. Biochim Biophys Acta 1997;1360:222-228.

26. Cadenas E, Varsavsky AI, Boveris A, Chance B. Oxygen or organic hydroperoxide-induced chemiluminescence of brain and liver homogenates. Biochem I 1981;198:645-654.

27. Krawiz JE, Sharon P, Stenson WF. Quantitative assay for acute intestinal inflammation based on myeloperoxidase activity. Assessment of inflammation in rat and hamster models. Gastroenterology 1984;87:13441350.

28. Grisham MB, Benoit JN, Granger DN. Assessment of leukocyte involvement during ischemia and reperfusion of intestine. Methods Enzymol 1990;186:729-742.

29. Carreras MC, Pargament GA, Catz SD, Poderoso JJ, Boveris A. Kinetics of nitric oxide and hydrogen peroxide production and formation of peroxynitrite during the respiratory burst of human neutrophils. FEBS Lett 1994;341:65-68.

30. Boveris A, Cadenas E. Cellular sources and steady state levels of reactive oxygen species. In: Biadasz Clerch L, Massaro DJ, eds. Oxygen, Gene Expression and Cellular Function. New York: Dekker, 1997:1-25.

31. Kakinuma K, Cadenas E, Boveris A, Chance B. Low level chemiluminescence of intact polymorphonuclear leukocytes. FEBS Lett 1979;102:38-42.

32. Zinner K, Vidigal-Martinelli C, Duran N, Marsaioli AJ, Cilento G. A new source of carbon oxides in biochemical systems. Implications regarding dioxetane intermediates. Biochem Biophys Res Commun 1980;92:32-37.

33. Poderoso JJ, Carreras MC, Lisdero CL, Riobo N, Schopfer F, Boveris A Nitric oxide inhibits electron transfer and increases superoxide radical production in rat heart mitochondria and submitochondrial particles. Arch Biochem Biophys 1996;328:85-92.

34. Poderoso JJ, Peralta JG, Lisdero CL, Carreras MC, Radisic M, Schopfer F, Cadenas $E$, et al. Nitric oxide regulates oxygen uptake and hydrogen peroxide release by the isolated beating rat heart. Am J Physiol 1998;274:C112-C119.

35. Calley MP, Kamei T, Flye W. Kupffer cell blockade increases mortality during intra-abdominal sepsis despite improving systemic immunity. Arch Surg 1990;125:36-41.

36. Shibuya H, Ohkohchi N, Tsukamoto S, Satomi S. Tumor necrosis factor-induced, superoxide-mediated neutrophil accumulation in cold ischemic/repefused rat liver. HePATOlogy 1997;26:113-120.

37. Zhou W, McCollum MO, Levine BA, Olson MS. Inflammation and platelet-activating factor production during hepatic ischemia/reperfusion. Hepatology 1992;16:1236-1240.

38. Serizawa A, Nakamura S, Suzuki S, Baba S, Nakano M. Involvement of platelet-activating factor in cytokine production and neutrophil activation after hepatic ischemia-reperfusion. Hepatology 1996;23:16561663

39. Hotter G, Closa D, Prats N, Pi F, Gelpi E, Rosellò-Catafau J. Free radical enhancement promotes leucocyte recruitment through a PAF and $\mathrm{LTB}_{4}$ dependent mechanism. Free Radic Biol Med 1997;22:947-954.

40. Rowell DL, Eckmann L, Dwinell MB, Carpenter SP, Raucy JL, Yang SK, Sagnoff MF. Human hepatocytes express an array of proinflammatory cytokines after agonist stimulation or bacterial invasion. Am J Physiol 1997;273:G322-G332.

41. Babior BM . Oxygen-dependent microbial killing by phagocytes. N Engl J Med 1978;298:659-668.

42. Carreras M C, Poderoso J], Cadenas E, Boveris A. M easurement of nitric oxide and hydrogen peroxide production by human neutrophils. M ethods Enzymol 1996;269:65-75.

43. Dahm LJ, Schultze AE, Roth RA. Activated neutrophils injure the isolated, perfused rat liver by an oxygen radical-dependent mechanism. Am J Pathol 1991;139:1009-1020.

44. Weiss SJ. Tissue destruction by neutrophils. N Engl J M ed 1989;320:365376.

45. Beckman JS, Beckman TW, Chen J, Marshall PA, Freeman BA. Apparent hydroxyl radical production by peroxinitrite: implications for endothelial injury from nitric oxide and superoxide. Proc Natl Acad Sci U S A 1990;87:1620-1624.

46. Allen RC, Atjernholm RL, Steele RH. Evidence for generation of an electronic excitation state(s) in human polymorphonuclear leukocytes and its participation in bactericidal activity. Biochem Biophys Res Commun 1972:47:679-684.

47. Badwey JA, Karnovsky ML. Active oxygen species and the functions of phagocytic leukocytes. Annu Rev Biochem 1980;49:695-726.

48. Steinbeck MJ, Khan AU, Karnovsky MJ. Intracellular singlet oxygen generation by phagocytosing neutrophils in response to particles coated with a chemical trap. J Biol Chem 1992;267:13424-13433.

49. Di Mascio P, Bribika K, Bechara EJ, Medeiros MH, Sies H. Reaction of peroxynitrite and hydrogen peroxide to singlet molecular oxygen. Methods Enzymol 1996;269:395-400. 